\title{
The InfLUenCe OF CUTTINg Edge RAdiUS Size ON THE TOOL LIFE OF CEMENTEd CARBIDE DRILlS
}

\author{
Tomáš Vopát, Marcel Kuruc, Vladimír Šimna, Martin Necpal, \\ Ivan Buranský, Rudolf Zaujec, Jozef Peterka
}
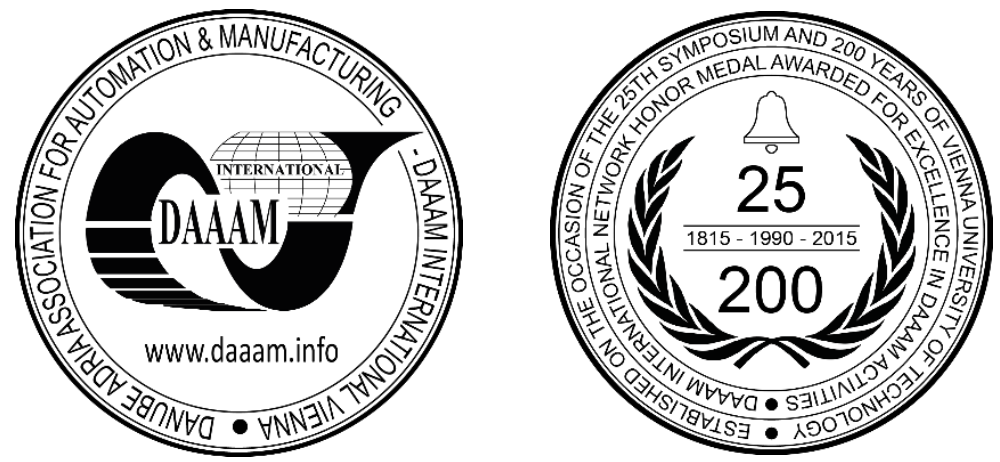

This Publication has to be referred as: Vopat, T[omas]; Kuruc, M[arcel]; Simna, V[ladimir]; Necpal, M[artin]; Buransky, I[van]; Zaujec, R[udolf] \& Peterka, J[ozef] (2018). The Influence of Cutting Edge Radius Size on the Tool Life of Cemented Carbide Drills, Proceedings of the 29th DAAAM International Symposium, pp.0421-0425, B. Katalinic (Ed.), Published by DAAAM International, ISBN 978-3-902734-20-4, ISSN 1726-9679, Vienna, Austria DOI: $10.2507 / 29$ th.daaam.proceedings.062

\begin{abstract}
The paper deals with the issue of cutting edge radius sizes their influence on the tool life of coated cemented carbide drills. Theoretical analysis was focused to the issue of cutting edge microgeometry, discussing the classification and importance of cutting edge microgeometry. The most famous and used edge preparation methods are summarized in this article. The tool lives of cemented carbide drills were compared when cutting edge radius was varied. Cemented carbide drills were deposited by TiAlN coating. Tool life tests were carried out on EMAG VSC 400 machining centre. These results were investigated in the process of machining of EN-GJL-250 grey cast iron (equivalent to DIN GG25, equivalent to ASTM A48).
\end{abstract}

Keywords: cutting edge preparation; treatment; cemented carbide, cutting tool; cutting edge microgeometry

\section{Introduction}

The cutting edge geometry and the applied edge preparation methods affect the tool wear of coated cutting tools [1], [2] and [3]. A thorough study of the efficiency of various cutting edge rounding methods as well as the effects of these treatments on the wear behavior of coated tools in milling various metallic materials is introduced in [1].

In terms of edge characterization, it has thus far been expedient in most instances to specify the geometry of honed edges by a simple edge radius parameter. This inherently assumes the edge profile that bridges the rake and flank faces to conform to an arc of a circle. This need not however be the case, and indeed tool performance may be enhanced by rendering the cutting edge to be appropriately asymmetric [4]. Given the critical influence of edge geometric attributes on process responses, and the evolving capability of aforementioned novel processes in the generation of tailored cutting edges, it is imperative to develop methodologies for the comprehensive geometric characterization of the cutting edge. Publication [2] deals with the complexity of cutting edge microgeometry and evaluates its interactions with machining processes. In the experiment, Yue et al. [5] showed that surface quality of MgAl2O4 spinel to be related to cutting speed, feed and the cutting edge radius of the diamond tool. 
Using sharp diamond tools can facilitate the ductile-regime turning of MgAl2O4 spinel, and has considerable potential to reduce surface roughness and produce smooth final surfaces for the brittle and hard materials. In the article [6], the influence of cutting edge radius sizes on the tool life was investigated. Prepared cemented carbides turning inserts with required cutting edge radii $r_{n}=24,44,64 \mu \mathrm{m}$ and unprepared cemented carbide turning inserts with cutting edge radii $r_{n}$ $=11.49 \mu \mathrm{m}$ were tested. Furthermore, the various edge preparation methods were compared in term of tool life of turning inserts. Vopat et al. determined that the tool life of prepared cemented carbide turning inserts by brushing is approximately the same as tool life of prepared cemented carbide turning inserts by wet microblasting for cutting edge radii smaller than $45 \mu \mathrm{m}$. The tool life of turning cemented carbide inserts prepared by brushing is approximately $32 \%$ longer than cemented carbide turning inserts prepared by wet microblasting for cutting edge radius $r_{n}=64 \mu \mathrm{m}$. The results show that the tool life of cemented carbide turning inserts increases when cutting edge radius is smaller. In addition, the tool life of unprepared cemented carbide turning inserts is longer than prepared ones. This phenomenon occurs during the machining of austenitic stainless steel material when cutting parameters as depth of cut and feed are selected for semi-finishing and finishing operations.

Publication [7] is concerned with the requirements and challenges in preparing and designing the cutting edge micro shape using wet abrasive jet machining. Wet abrasive jet machining with a robot guided system allows to prepare local tool areas and to realize a specific design of the cutting edge, as well as advantageous surface qualities. Yussefian et al. [8] investigated sink electrical discharge machining as an optional method for controlled preparing of cutting edges by sinking the cutting edge into a counterface. Although the manufactured rounding variability is stated as minimal, the capability to prepare straight cutting edges is not limited by the tools' material hardness.

The application of laser machining for manufacturing the cutting edge roundness of cemented carbide inserts could have a beneficial effect on the wear behaviour of coated tools. The main advantage of using laser machining for manufacturing the cutting edge radii is the achievement of a reproducible micro-geometry [9] and [10] as well as the capability of versatile application with respect to manufacturing of complex-shaped geometries and setting up high surface qualities for cemented carbide tools [11]. In [12], the feasibility of using laser machining for manufacturing the cutting edge roundness of cemented carbide inserts was investigated. In this context, diverse laser machining parameters such as of the laser-pulsing duration and -beam feed velocity were applied for shaping the cutting edge roundness. Hereupon, shorter laser pulsing durations in the order of pico-seconds and larger feed velocities eliminate the negative effects of a thermal affected zones associated with its thickness, material properties and adhesion on the coated tool life. Moreover, the conduct of micro-blasting on the already laser-treated cemented carbide substrates increases the effective coating adhesion, thus leading to a cutting performance improvement of the coated tools.

The Publication [13] evaluated the relationship between the cutting edge radius and the immersion depth during the drag finishing process. The smallest radius of $8.1 \mu \mathrm{m}$ was measured in a depth of $330 \mathrm{~mm}$. The value of the radius increased to $14.6 \mu \mathrm{m}$ in the depth of $430 \mathrm{~mm}$. Besides, deeper immersion depth caused a higher intensity of cutting edge modification where marks after grindstone disappeared from flank and rake face. Another advantage is that the symmetry of cutting edge is achieved after drag finishing.

The article [14] dealt with the influences of the cutting edge radius on the workpiece surface roughness. Three variants of cutting edge radius $(15 \mu \mathrm{m}, 20 \mu \mathrm{m}$ and $25 \mu \mathrm{m})$ were tested during the experiment. Authors determined that larger cutting edge radius caused an increase of surface roughness parameters Ra; Rz; Sa. In [15] authors investigated influence of the cutting edge preparation on tool life of cemented carbide inserts when milling.

Publication [16] deals with testing cemented carbide cutting tools with different cutting edge qualities obtained by different grinding conditions during the experimental cutting of Inconel 718 super-alloy.

In terms of edge characterization, it has thus far been expedient in most instances to specify the geometry of honed edges by a simple edge radius parameter. This inherently assumes the edge profile that bridges the rake and flank faces to conform to an arc of a circle. This need not however be the case, and indeed tool performance may be enhanced by rendering the cutting edge to be appropriately asymmetric [4]. Given the critical influence of edge geometric attributes on process responses, and the evolving capability of aforementioned novel processes in the generation of tailored cutting edges, it is imperative to develop methodologies for the comprehensive geometric characterization of the cutting edge.

In publication [17], Denkena et al. presents a novel method for preparing of customized cutting edges by means of grinding. The reliability of the new method has been proven and the dependency of the obtained relative error on the chamfer size discussed. Moreover, an evaluation of the edge chipping has been carried out. It has been shown that preparing the edge as proposed by the method reduces the edge chipping by approximately $1 \mu \mathrm{m}$ in comparison to a sharp edge. Varying the micro geometry does not lead to a variation of the edge chipping. Influence of used edge preparation method on the coating adhesion to substrate is discussed in [18].

It is a well-known fact that cutting tool wear is a function of basic process parameters. The publications in introduction presented that cutting the edge microgeometry has a great influence on the tool life. The aim of this article was to investigate influence of cutting edge radius $r_{n}$ sizes on the tool life in machining of EN-GJL-250 cast iron material.

\section{Materials and methods}

With support of the Staton, s.r.o. Company, drag finishing as edge preparation method was used. Cemented carbide drills were manufactured with the two cutting edge radius sizes: $r_{n}=15 \mu \mathrm{m}( \pm 2 \mu \mathrm{m})$ and $r_{n}=25 \mu \mathrm{m}( \pm 2 \mu \mathrm{m})$. 
After drag finishing, all cemented carbide drills were cleaned and then they were deposited by TiAlN coating when deposition conditions were constant. MikroCAD Plus optical measurement device was used to measure the cutting edge radius sizes. The solid cemented carbide drills MZS1150MB with cutting dimeter of $11.5 \mathrm{~mm}$, shank diameter of $12 \mathrm{~mm}$, point angle of $140^{\circ}$, usable cutting length of $36.6 \mathrm{~mm}$, length chip flute of $59.6 \mathrm{~mm}$, functional length secondary of 62.1 $\mathrm{mm}$ and overall length of $124.1 \mathrm{~mm}$ was selected for this research. The selected workpiece material was gray cast iron material grade EN-GJL-250. Chemical composition is shown in Table 1.

\begin{tabular}{|c|c|c|c|c|c|}
\hline Element & $\mathbf{C}$ & Si & Mn & P & S \\
\hline wt. \% & $2.90-3.65$ & $1.80-2.90$ & $0.40-0.90$ & max. 0.30 & max. 0.10 \\
\hline
\end{tabular}

Table 1. Chemical composition of EN-GJL-250 gray cast iron material

Cemented carbide drills were tested on the multifunctional vertical turning centre. Cemented carbide drills were clamped in ER collet chuck toolholder. Coolant was used in the machining process. The cutting parameters (cutting speed, feed and depth of cut) of cemented carbide drills are shown in Table 2. The depth of drilling was $11.5 \mathrm{~mm}$.

\begin{tabular}{|c|c|c|}
\hline cutting speed $\boldsymbol{v}_{\boldsymbol{c}}(\mathbf{m} / \mathbf{m i n})$ & feed $\boldsymbol{f}(\mathbf{m m})$ & depth of cut $\boldsymbol{a}_{\boldsymbol{p}}(\mathbf{m m})$ \\
\hline 100 & 0.4 & 5.75 \\
\hline
\end{tabular}

Table 2. Cutting parameters for coated cemented carbide drills

In this article, a typical tool wear types of cutting tool were not observed in machining process. Tool life was investigated in order to quality of machined hole. The machining tests were stopped when there was reached the one of the following three defects:

- hole diameter was outside the tolerance $( \pm 0.2 \mathrm{~mm})$

- or surface roughness parameter $R a$ was exceeded $(R a>6.3 \mu \mathrm{m})$

- or workpiece material was remained on the edges of the holes (Fig. 1).

It follows that tool life criterion was the number of holes which were drilled without previous defects. Every type of cemented carbide drills (the same cutting edge radius $r_{n}$ ) was tested three times in order to exclude the impact of other factors involved in the process. After that, the average value was calculated.
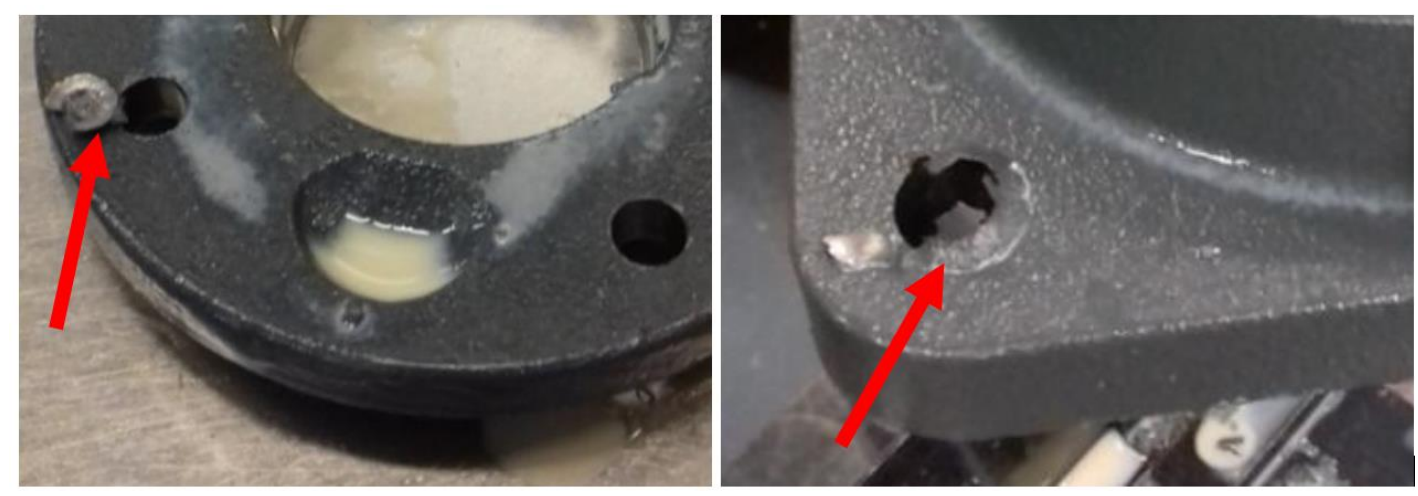

Fig. 1. Remained material on the edges of the holes

\section{Results and discussion}

The graph in Fig. 4 shows tool life of cemented carbide drills (the number of holes which were drilled without defects) in order to cutting edge radius size of cemented carbide drills. The tool life of cemented carbide drills was obtained as average value of three measurements. Standard deviations are also inserted to the graph in Fig. 2.

Tool life of cemented carbide drills with cutting edge radius $r_{n}=15 \mu \mathrm{m}$ was 1230 drilled holes without defects and tool life of cemented carbide drills with cutting edge radius $r_{n}=25 \mu \mathrm{m}$ was 3233 drilled holes without defects.

The results show that the tool life of cemented carbide drills increases when cutting edge radius is larger. The tool life of cemented carbide drills with cutting edge radius $r_{n}=25 \mu \mathrm{m}$ is approximately $163 \%$ longer than cemented carbide drills with cutting edge radius $r_{n}=15 \mu \mathrm{m}$. 


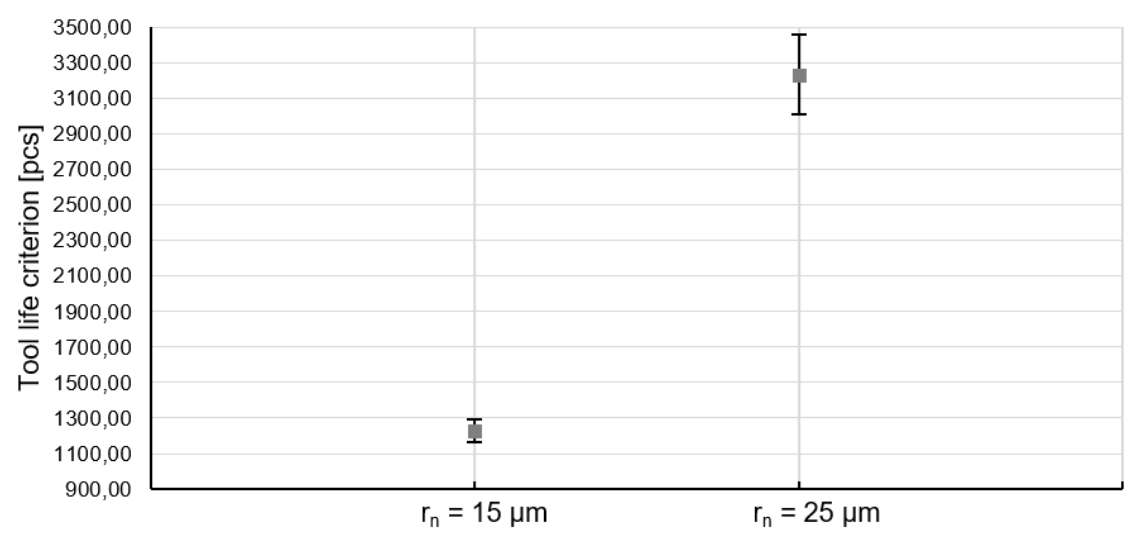

Fig. 2. Graph of tool life of cemented carbide drills with various cutting edge radius size

\section{Conclusion}

In this article, the influence of cutting edge radius sizes on the tool life of cemented carbide drills was investigated. Solution to this issue consists of the following steps: cutting edge preparation and surface treatment, cleaning, PVD coating, measurement of cemented carbide drills, tool life tests and evaluation. Tested cutting tool material was cemented carbide and selected workpiece material was EN-GJL-250 grey cast iron. Cemented carbide drills were deposited by TiAlN coating. Tool life was investigated in order to quality of machined hole. The machining tests were stopped when there was reached the one of the following three defects: hole diameter was outside the tolerance $( \pm 0.2 \mathrm{~mm})$ or surface roughness parameter $R a$ was exceeded $(R a>6.3 \mu \mathrm{m})$ or workpiece material was remained on the edges of the holes.

Prepared cemented carbide drills with required cutting edge radii $r_{n}=15$ and $25 \mu \mathrm{m}$ were tested. The tool life of cemented carbide drills with cutting edge radius $r_{n}=25 \mu \mathrm{m}$ is approximately $163 \%$ longer than cemented carbide drills with cutting edge radius $r_{n}=15 \mu \mathrm{m}$. The results show that the tool life of cemented carbide drills increases when cutting edge radius is larger.

In the future research, authors are going to focus on investigation of issue of cutting edge microgeometry during the machining the difficult-to-materials material such as Inconel superalloy and stainless steel. Authors are also going to determine the influence of edge preparation on the tool life of cemented carbide turning inserts and cemented carbide milling cutters.

\section{Acknowledgments}

The article was written with the support of the Project of VEGA grant agency of the Ministry of Education, Science, Research and Sport of the Slovak Republic and Slovak Academy of Sciences, no. 1/0097/17: "The research of novel method for cutting edge preparation to increase the tool performance in machining of difficult-to-machine materials", and APVV Project of Slovak Research and development Agency of the Ministry of Education, Science, Research and Sport of the Slovak Republic, no. APVV-16-0057: "Research into the Unique Method for Treatment of Cutting Edge Microgeometry by Plasma Discharges in Electrolyte to Increase the Tool Life of Cutting Tools in Machining of Difficultto-Machine Materials."

This article was also supported by Staton, s.r.o. Authors are also grateful to Michal Durina, who participated in this research.

\section{References}

[1] Bouzakis, K.-D., Bouzakis, E., Kombogiannis, S., Makrimallakis, S., Skordaris, G., Michailidis, N., Charalampous, P., Paraskevopoulou, R., M'Saoubi, R., Aurich, J.C., Barthelmä, F., Biermann, D., Denkena, B., Dimitrov, D., Engin, S., Karpuschewski, B., Klocke, F., Özel, T., Poulachon, G., Rech, J., Schulze, V., Settineri, L., Srivastava, A., Wegener, K., Uhlmann, E., Zeman, P. (2014). Effect of Cutting Edge Preparation of Coated Tools on Their Performance in Milling Various Materials. CIRP Journal of Manufacturing Science and Technology, 7 (3), pp. 264273

[2] Denkena, B., Biermann, D. Cutting Edge Geometries. (2014). CIRP Annals - Manufacturing Technology, Volume 63, pp. 631-653

[3] Uhlmann, E., Oberschmidt, D., Löwenstein A., Kuche, Y. (2016). Influence of Cutting Edge Preparation on the Performance of Micro Milling Tools. Procedia CIRP. Volume 46, Pages 214-217

[4] Denkena, B., Lucas, A., Bassett. (2011). E. Effects of the cutting edge microgeometry on tool wear and its thermo mechanical load. CIRP Annals - Manufacturing Technology, Volume 60, pp. 73-76 
[5] Yue, X., Xu, M., Du, W., Chu, C. 2017. Effect of cutting edge radius on surface roughness in diamond tool turning of transparent $\mathrm{MgAl} 2 \mathrm{O} 4$ spinel ceramic. Opt Mater, 71, pp. 129-135

[6] Vopát, T., Kuruc, M., Šimna, V., Zaujec, R., Peterka, J. (2017). Cutting edge microgeometry and preparation methods. Annals of DAAAM International 2017, Volume 28, No.1, pp. 384-391, ISSN 2304-1382, ISBN 978-3902734-14-3. Ed. B. Katalinic, Published by DAAAM International, Vienna, Austria.

[7] Biermann, D., Aßmuth, R., Schumann, S., Rieger, M., Kuhlenkötter, B. (2016). Wet Abrasive Jet Machining to Prepare and Design the Cutting Edge Micro Shape. Procedia CIRP, Volume 45, pp.195-198

[8] Yussefian, N.Z., Koshy, P., Buchholz, S., Klocke F. (2010). Electro-erosion Edge Honing of Cutting Tools. CIRP Annals, Volume 59 (1), pp. 215-218

[9] Breidenstein, B., Gey, C., Denkena, B. (2013). Surface Integrity of Laser Machined Carbide Cutting Tools Within the PVD-coating Process Chain Materialwissenschaft und Werkstofftechnik, Volume 44 (8), pp. 704-709

[10] Aurich, J.C., Zimmermann, M., Leitz, L. (2011). The Preparation of Cutting Edges Using a Marking Laser Production Engineering -Research and Development, Volume 5 (1), pp. 17-24

[11] Uhlmann, E., Richarz, S., Mihotovic, V. (2009). Substrate Pre-treatment of Cemented Carbides using Abrasive Flow Machining and Laser Beam Ablation. Production Engineering, Volume 3 (1), pp. 81-86

[12] Bouzakis, K.-D., Charalampous, P., Kotsanis T., Skordaris, G., Bouzakis, E., Denkena, B., Breidenstein, B., Aurich, J.C., Zimmermann, M., Herrmann, T., M'Saoubi, R. (2017). Effect of HM substrates' cutting edge roundness manufactured by laser machining and micro-blasting on the coated tools' cutting performance. CIRP Journal of Manufacturing Science and Technology. Volume 18, pp. 188-197

[13] Hronek, O., Zetek, M., Baksa, T. (2017). The immersion depth influences on cutting edge radius during drag finishing. Annals of DAAAM International 2017, Volume 28, No.1, pp. 1030-1036, ISSN 2304-1382, ISBN 978-3902734-14-3. Ed. B. Katalinic, Published by DAAAM International, Vienna, Austria.

[14] Hronek, O., Zetek, M. (2017). The influences of cutting edge radius on surface roughness when milling nickel alloy. Annals of DAAAM International 2017, Volume 28, No.1, pp. 1037-1043, ISSN 2304-1382, ISBN 978-3-90273414-3. Ed. B. Katalinic, Published by DAAAM International, Vienna, Austria.

[15] Fulemová, J., Řehoř, J. (2015). Influence of form factor of the cutting edge on tool life during finishing milling. Procedia Engineering, Volume 100, pp. 682-688.

[16] Baksa, T., Schornik, V., Adamek, P., Zetek, M. (2016). Machining of inconel 718 using uncoated cutting tools with different cutting edge quality. Annals of DAAAM and Proceedings of the International DAAAM Symposium, Volume 27, Issue 1, pp. 441-446.

[17] Denkena, B. Kohler, J. Ventura, C.E.H. (2013). Customized cutting edge preparation by means of grinding. Volume 37, Issue 3, pp. 590-598.

[18] Vopát, T., Haršáni, M., Kuruc, M., Šimna, V., Zaujec, R., Peterka, J., Čaplovič, L'. (2017). Effect of Substrate Bias and Coating Thickness on the Properties of nc-AlCrN/a-SixNy Hard Coating and Determination of Cutting Parameters. Solid State Phenomena. Volume 261, pp. 229-236. 